\title{
A Theoretically Grounded Framework for Integrating the Scholarship of Teaching and Learning
}

\begin{abstract}
Jill K. Walls1
Abstract: SoTL scholars have written about the importance and utility of teaching from a guiding theoretical framework. In this paper, ecological theory and specifically Bronfenbrenner's bioecological model, is examined as a potential framework for synthesizing SoTL research findings to inform teaching and learning scholarship at the college level. A general overview of the bioecological model of human development and its application to the SoTL literature are provided. The benefit of adopting an ecologically-based framework to better understand and exploit the interdisciplinary nature of SoTL is discussed.
\end{abstract}

Keywords: ecological theory, bioecological model, college/university teaching, theory, SoTL.

\section{Introduction}

SoTL scholars have written about the importance and utility of working from a guiding theoretical framework when teaching and conducting research, yet a theoretically grounded framework for integrating scholarship on teaching and learning is absent from the SoTL literature (Felten, 2013). There is a need for a clear, systematic way of mapping out SoTL research that allows scholars to synthesize and assess SoTL literature related to their research questions and projects, identify gaps and limitations of prior work, and see how their work fits into the broader SoTL landscape. Utilizing an explicit theoretical framework to weave together studies from diverse disciplines allows for a more systematic and meaningful integration of findings from SoTL research. Moreover, an integrative heuristic tool, such as a theory-based framework, can provide a "big picture" view of interrelated studies and a deeper understanding of how research findings overlap and intersect across disciplines.

The scope of SoTL research is rather broad and diverse because of its interdisciplinary nature. As a result, it can be daunting to see how individual studies fit together particularly for scholars who are new to SoTL. Because SoTL is "happening" in so many areas of study, a theoretical framework that brings together seemingly disparate findings is needed. As Kern, Mettetal, Dixson, and Morgan (2015) noted, “... as SoTL has grown, the connections across the disciplines have blossomed, thus enriching the scholarship of integration. While some ways of knowing are unique to particular disciplines, there is much that is and will be shared across the disciplines" (p. 7). Although there has been a push for cross-disciplinary approaches to SoTL, Cassard and Sloboda (2014) pointed out that, "...not all disciplines speak in the same language", which can present an inherent challenge when scholars from various disciplines attempt to collaborate on SoTL projects (p. 48). A theoretical framework that extends across disciplines provides a starting point for collaborative work such that scholars come together with at least some

${ }_{1}$ Department of Family and Consumer Sciences, Ball State University, 2000 W. University Ave., Muncie, IN 47306, jkwalls2@bsu.edu. 
shared understanding. Theory provides a common language for teacher-scholars to benefit from the interdisciplinary nature of SoTL such that they might be more likely to investigate and apply "lessons learned" from other disciplines.

An ecological approach to teaching and learning aligns with other "whole student" models of instruction in that it promotes inclusivity and student-centered approaches to instruction. Howie (2013), for example, discussed the application of Bronfenbrenner's ecological theory to teaching young children and its utility in promoting inclusive educational environments through promoting school-family partnerships, and attending to shared and individual needs of students from all 'ecological niches'. In this paper I propose Bronfenbrenner's bioecological model as a theoretical framework for integrating research on teaching and learning in higher education. The bioecological model is appropriate for this use because of its developmental orientation and broad applicability. Student learning is the centerpiece of SoTL and learning is, after all, a developmental process. The bioecological model is studied in many disciplines and broad enough to capture proximal and distal influences on student learning, while attending to individual variation and student-environment interactions.

The proposed application of the bioecological model to frame SoTL research has the potential to highlight the interconnectedness of research from a variety of academic disciplines, promote cross-disciplinary conversations in SoTL, and bring clarity to "best practices" discovered in multiple academic disciplines. A general overview of the bioecological model is followed by an illustration of how the model could be used to identify studies and develop an educational workshop intended to promote excellence in teaching among new faculty. Many doctoral programs place heavy emphasis on research training and mastery of content knowledge, with less emphasis on how to teach and teaching pedagogy. As a result, new faculty might come to a university with limited teaching experience and training. Colleges and universities who provide additional training and mentoring to new faculty not only improve quality of instruction but also increase confidence and reduce feelings of isolation among new faculty (Savage, Karp, \& Logue, 2004). A sample (but not an exhaustive review) of current studies is provided to demonstrate the utility of the bioecological model as a framework for synthesizing SoTL research, and specifically for the development of a teaching-oriented workshop for new faculty. The benefit of adopting an ecologically-based framework to better understand and exploit the interdisciplinary nature of SoTL is discussed.

\section{Ecological Theory in a Nutshell}

According to Bronfenbrenner $(1979,1988)$, human development is a process that occurs as a joint function of characteristics of the individual and environmental context. In his later work, Bronfenbrenner and Morris $(1998,2006)$ proposed a comprehensive bioecological model of development that involved four central components: Process, Person, Context, and Time. Central to the bioecological model are proximal processes, or the regular interactions that occur between the developing person and his/her environment (Bronfenbrenner \& Ceci, 1994). Bronfenbrenner described proximal processes as the driving forces behind development and emphasized that such interactions needed to occur on a regular basis and become increasingly complex over time in order to promote development.

Person-environment interactions were theorized to vary as a function of individual characteristics (i.e., the Person dimension of the model). Person characteristics affect proximal processes and subsequent development by interacting with one's environment in a number of

Journal of the Scholarship of Teaching and Learning, Vol. 17, No. 2, April 2017.

josotl.indiana.edu 
ways. For example, genetically-based factors such as personality traits, sex, ethnicity, and physical attractiveness can elicit different responses from one's environment. Those same characteristics may bring with them resources or deficiencies that place individuals in a position of social advantage or disadvantage. Individuals, by virtue of their unique qualities, are attracted to different aspects of their social, psychological, physical, and symbolic environments. As individuals selfselect into different environments, their knowledge and skills are uniquely shaped; similarly, as individuals become increasingly complex beings, they begin to actively structure or shape aspects of their environments in more complex ways.

Proximal processes are shaped directly and indirectly by various ecological systems (i.e., the Context dimension of the model). Individuals' immediate environments, or microsystems, include their families, workplaces, and academic institutions. The interaction of two or more microsystems, such as the overlap between school and home contexts, is called the mesosystem (Bronfenbrenner \& Ceci, 1994). Exosystems involve indirect effects of the environment on development, such as the effect of parents' workplace on their children. The broadest and most distal context from the developing individual is the macrosystem, which includes the effects of culture on development.

Bronfenbrenner conceptualized time in a number of ways, from the moment-to-moment exchanges that take place between individuals and their environments (i.e., proximal processes) to events that occur over longer periods of time, including how person-environment interactions are shaped by the historical time in which they occur.

Taken together, the bioecological model is a framework for understanding human development that includes unique characteristics of individuals, the regular interactions they have with their environments, the contexts in which they are directly and indirectly situated, and time. The model integrates both proximal and distal influences on human development, taking into account how personal and contextual factors interact to produce varied results. In other words, this theoretical perspective considers the "whole person" situated in context.

\section{The Bioecological Model as a Framework for Integrating SoTL Research}

The bioecological model was originally proposed as a theoretical framework for empirical research on human development from an ecological perspective (Bronfenbrenner \& Morris, 1998, 2006). Scholars across various academic disciplines continue to use parts of Brofenbrenner's theoretical work to frame their research questions and methodologies. For example, ecological theory has been used to frame research questions that examine factors associated with academic success (e.g., Stewart, 2006). In addition, ecological systems theory and the bioecological model are taught to undergraduate and graduate students in many academic programs. Because scholars from a variety of disciplines are likely familiar with an ecological approach, broadly speaking, the bioecological model can be a user-friendly tool for synthesizing SoTL literature and provides some "common language" for collaborative work in the scholarship of teaching and learning. The bioecological model is a useful framework for integrating SoTL research studies as it calls attention to multiple influences on teaching and learning.

Journal of the Scholarship of Teaching and Learning, Vol. 17, No. 2, April 2017.

josotl.indiana.edu 
The bioecological model is proposed as a general framework for integrating SoTL findings in a meaningful and theoretically relevant way. This contextual and cross-disciplinary framework can be used to provide a cohesive look at students' personal and collective educational experiences, with a consideration for the broader contexts that may have a bearing on student learning (directly or in conjunction with other factors) over time. Figure 1 provides a visual depiction of the bioecological model and its four components (Process, Person, Context, and Time). Below each component I've listed variables that are identified in current SoTL research as relevant to student learning and could be included in a workshop geared meant to foster excellence in teaching among new faculty.

Figure 1. A visual depiction of the Bioecological Model used as a framework for organizing SoTL topics relevant to excellence in teaching.

\section{The Process Dimension}

Proximal processes refer to ongoing, regular student-environment interactions that occur over a period of time. A teaching-oriented workshop for new faculty would emphasize factors that promote positive studentinteractions, proximal influence student learning SoTL research suggests their instructors are interact, teachers' nature of the interactions report of the National

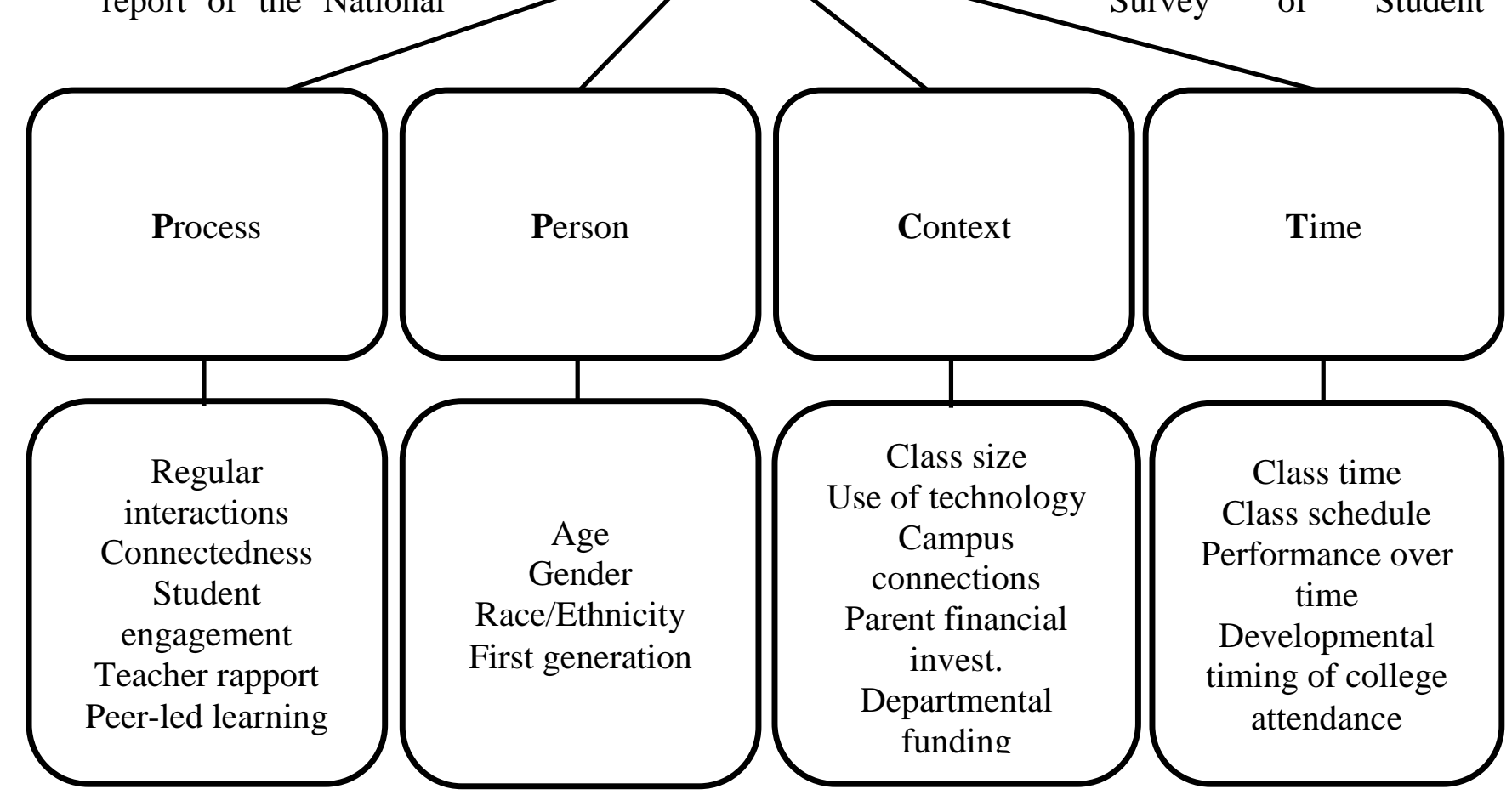

Engagement (NSSE, 2013), regular student-teacher interactions were found to be valuable to student learning. Students feel more confident and perform better in classes where they feel a Journal of the Scholarship of Teaching and Learning, Vol. 17, No. 2, April 2017. josotl.indiana.edu 
connection to the professor (Micari \& Pazos, 2012). Active and collaborative approaches encourage student-peer interactions and promote higher-order thinking and complex reasoning (Driscoll, 2000; Michel, Cater, \& Varela, 2009). Student learning is enhanced when instructors promote small and large group discussions, and some studies suggest benefits of student-led group discussions over teacher-led discussions (Yoder \& Hochevar, 2005).

University instructors who have been highly regarded for their teaching attend to and care about their students and the multiple factors that influence their learning (Jenkins \& Speck, 2007). Christenbury (2011) contended that instructors are at their best when they are flexible, attending to the classroom context and students' needs, instead of operating from a rigid teaching plan. In a recent study of instructional effectiveness, graduate students identified the emotional context in which learning takes place as being as important as professors' content knowledge (Hill, 2014). The positive effects of teacher-student interactions on student learning are to some degree facilitated by the degree to which students are emotional engaged in their coursework (Sagayadevan \& Jeyaraj, 2012).

Informed by the literature, a teaching-oriented workshop could highlight ways in which faculty can be intentional about building rapport with their students through attentiveness, efforts to build trust, courtesy, and being relatable (Frisby \& Myers, 2008). In addition, the workshop would emphasize the importance of regular student-teacher interactions and the value of active learning opportunities.

\section{The Person Dimension}

The Person dimension calls attention to individual sources of variability. In this example, a teaching-oriented workshop for new faculty would highlight student characteristics that are salient to their learning. Inclusive teaching practices that attend to individual sources of variability promote mutual respect within the classroom, increased awareness of diverse perspectives, and prepare students for a world that is indeed diverse (Bigatti et al., 2012; Wentzell, Richlin, \& Cox, 2010). Therefore, instructors must be aware of student characteristics that are meaningful for their academic experiences such as their year of study (e.g., freshman, sophomore ...), age, gender, sexual orientation, family history (e.g., parents' educational attainment), ethnicity, religious background, English fluency/ literacy, exposure to diverse populations prior to college, and socioeconomic status, to name a few. A teaching-oriented workshop might prepare new faculty to work with specific subgroups of students such as millennials and first generation college students (McGlynn, 2008; Pascarella, Pierson, Wolniak, \& Terenzini, 2004). In addition, new faculty would benefit from some guidance around adopting a multicultural approach to education, given its potential to increase cultural sensitivity among all students and reduce race-related stressors (e.g., racial stereotyping) among ethnic minority students (Bigatti et al., 2012; Harper, 2009).

\section{The Context Dimension}

Context refers to the environments in which learning takes place and that (directly or indirectly) impact classroom performance. The microsystem refers to students' immediate learning environments, which includes their classrooms and living spaces. Larger class size has been linked to poorer student and teacher performance, which suggests that teaching and learning challenges increase in proportion to the number of students in a given class (e.g., Bedard \& Kuhn, 2008; Chapman \& Ludlow, 2010). Advances in modern technology have had a dramatic impact on the

Journal of the Scholarship of Teaching and Learning, Vol. 17, No. 2, April 2017.

josotl.indiana.edu 
structure and setting of college classrooms. Studies of online learners suggest that they might need some additional accommodations in order to be successful such as technological help and sample assignments (Mupinga, Nora, \& Yaw, 2006). On campus, students' use of smartphones during class time is a distraction and has the potential to compromise grades (Synnott, 2015). Challenges in on-campus and virtual classrooms further underscore the significance of the emotional tone set by the instructor and its potential to influence student learning. While instructors have limited authority over some aspects of the immediate environment in which they teach (e.g., the classroom location, classroom size, seating, and available technology), they do have some influence over the emotional and intellectual context of the classroom. Thus a teaching-oriented workshop for new faculty might include activities to strengthen instructors' ability to develop positive connections with their students, or proximal processes, as mentioned previously.

The mesosystem includes the interactions that take place between two microsystems (i.e., teacher-to-teacher communication that takes place on behalf of a student) and their influence on student learning. A recent review of 38 studies suggested that instructors collaborate with student support services on campus as one step in practicing inclusive education and improving the educational experiences of students with disabilities (Orr \& Hammig, 2009). Disability services is just one example of a context that instructors might have to interact with on behalf of their students. Campus organizations, internship sites, and health services are other examples. Although newer faculty might know that these resources exist on campus, they might not know how or under what circumstances they should reach out to them.

The exosystem is a context that students are not directly situated, but has an indirect effect on their learning in the classroom nonetheless. Exosystem influences could also include environments not directly associated with the university setting. For example, Hamilton (2013) examined the effect of parents' financial contributions on students' academic success. Results from that study suggest that students who receive greater financial investment from their parents tend to receive lower grades, but are more likely to graduate than their peers. By acknowledging exosystem influences on students' performance in the classroom, teaching-oriented workshops promote greater sensitivity among new faculty.

The Macrosystem includes broader cultural forces, such as funding for academic programs and state and national priorities. Funding or lack of funding can impact course offerings, classroom size, access to technology, instructors' workload and their ability to effectively mentor students all of which affect student learning outcomes (Hearn \& Holdsworth, 2002). This too might be something new faculty know about, generally speaking, but with which they have little firsthand experience. As faculty gain experience and eventually tenure, they could find themselves serving on university committees and in leadership roles. Knowledge about macrosystem influences within an academic setting can assist instructors in making wise career-related decisions, being fiscally responsible, and navigating internal and external funding opportunities.

\section{The Time Dimension}

Time in Bronfenbrenner's theoretical work takes many forms. Human development and student learning are both fluid concepts that occur over time. In an academic setting we can consider the amount of time students spend in the classroom, how many days per week a class meets, the regularity with which teachers interact with individual students over time, or the time of day a class takes place. Some research suggests, for example, that optimal cognitive performance occurs in the afternoon for college students (Allen, Grabbe, McCarthy, Bush, \& Wallace, 2008). New

Journal of the Scholarship of Teaching and Learning, Vol. 17, No. 2, April 2017.

josotl.indiana.edu 
instructors whose classes fall outside that time frame might want to encourage students to adopt specific strategies that enable them to stay awake and engaged during class. The timing of students' college experience in their own developmental trajectory matters as well. For example, the learning needs and level of confidence in the classroom may be different for traditional and nontraditional students (Bishop-Clark \& Lynch, 1992). One study tracked students' academic goals, decision making, and self-evaluations across the first year of college, which might be useful information for new faculty in their mentoring/advising roles (Galotti \& Clare, 2014). Teachers often track students' performance over time and many programs have accountability measures in place that examine cohorts of students in particular classes over time. We can also consider how our teaching takes place within a historical time. The "state of education" looks differently today than it did 30 years ago. Priorities change, funding mechanisms change along with shifts in the economy, opportunities for international students change with the political landscape, and the expectations of instructors change, for example. Thus, the time component of the bioecological model prompts a consideration for what has already happened, what is happening now, and the potential for changes in the future with respect to both teaching and learning.

\section{Conclusion}

The scholarship of teaching and learning has been gaining momentum over the past two decades. As SoTL gains more recognition and support at academic institutions, scholars are expanding and possibly redefining their research agendas to examine teaching and learning within their own disciplines. In this paper the bioecological model is proposed as a theoretical framework for integrating SoTL research findings and facilitating interdisciplinary collaborations among faculty. An ecological theoretical framework is appropriate for synthesizing SoTL research because it draws attention to the dynamic interplay between students' individual characteristics and their learning environments, and how multiple factors (both inside and outside of the classroom) are important to consider as instructors prepare for a productive academic year.

The example provided in this paper demonstrates the utility of this type of framework for the development of a teaching-oriented workshop for new faculty. There are virtually endless suggestions one could give new faculty about how to be an effective instructor. By situating current SoTL research within a bioecological framework, the vast studies about "how to teach well" and "what matters" suddenly become more digestible, user-friendly, and theoretically grounded. It is noteworthy that the studies collected for the example application came from SoTL, economics, psychology, and Black studies journals. I've provided just one example of how this framework could be implemented; the application is not limited to the development of a new program or workshop. Scholars interested in specific topics, such as the use of technology in the classroom, or specific outcomes such as academic self-esteem, could explore how extant research fits into each of the four components of the model. This works as a starting point for scholars embarking on topics that are new to them, or a way of examining familiar literature from a new point of view.

Of course there are other frameworks that may be a useful heuristic for pulling together SoTL research; this is just one suggestion that seems to work. Many instructors are already referencing Bronfenbrenner's work in their research and the classes they teach, and therefore this theory may provide teacher-scholars from a variety of academic backgrounds with a common ground for collaborative work. Additionally, this framework could be useful for teacher-student collaborations on SoTL projects particularly if students are exposed to Bronfenbrenner's theorizing as part of their coursework. Because this is a developmental and contextual theory, it

Journal of the Scholarship of Teaching and Learning, Vol. 17, No. 2, April 2017.

josotl.indiana.edu 
can be applied to understand studies of teaching and learning across multiple settings and disciplines. This framework could be particularly useful for budding scholars who are considering SoTL as a main line of research but might have limited familiarity with learning theories. The bioecological model can also be used to evaluate seasoned instructors who may be looking for a way to monitor and improve their teaching. Instructors could provide evidence of how they attend to Process, Person, Context, and Time dimensions when teaching their courses. Indeed, it is easy to fall into a rut of teaching within one's comfort zone. The bioecological model sensitizes instructors to proximal and distal influences on student learning and this model can accommodate the ever-changing contexts in which learning takes place.

The bioecological model provides a comprehensive and contextual framework for understanding student development and academic success and can be applied to virtually any discipline because it directs our attention to the whole student and the many factors that influence student learning. Beyond a heuristic tool for promoting collaborative SoTL research, the application of the bioecological model as a framework for integrating SoTL studies may also be useful for the development of a comprehensive teacher training program.

\section{Acknowledgements}

I would like to thank Drs. Carol Friesen and Melinda Messino for their encouragement and thoughtful feedback on drafts of this manuscript. Gratitude is extended to Dr. Jonathan Tudge for providing me with a solid background in and appreciation for ecological theory in graduate school. Many thanks to Janet Nestor for her encouragement and support.

\section{References}

Allen, P. A., Grabbe, J., McCarthy, A., Bush, A. H., \& Wallace B. (2008). The early bird does not get the worm: Time-of-day effects on college students' basic cognitive processing. American Journal of Psychology, 121, 551-564.

Bedard, K., \& Kuhn, P. (2008). Where class size really matters: Class size and student ratings of instructor effectiveness. Economics of Education Review, 27, 253-265.

Bigatti, S. M., Gibau, G. S., Boys, S., Grove, K., Ashburn-Nardo, L., Khaja, K., \& Springer, J. T. (2012). Faculty perceptions of multicultural teaching in a large urban university. Journal of the Scholarship of Teaching and Learning, 12, 78-93.

Bishop-Clark, C., \& Lynch, J. M. (1992). The mixed-age college classroom. College Teaching, 40, 114-117.

Bronfenbrenner, U. (1979). The ecology of human development: Experiments by nature and design, American Psychologist, 32, 513-531.

Bronfenbrenner, U. (1988). Interacting systems in human development. Research paradigms: present and future. In N. Bolger et al. (Eds.), Persons in context: Developmental process. Human development in cultural and historical contexts. (pp. 25-49). New York: Cambridge University Press.

Journal of the Scholarship of Teaching and Learning, Vol. 17, No. 2, April 2017.

josotl.indiana.edu 
Bronfenbrenner, U., \& Ceci, S. J. (1994) Nature-Nurture reconceptualized in developmental perspective: A Bioecological model. Psychological Review, 101, 568 - 586.

Bronfenbrenner, U., \& Morris, P. A. (1998). The ecology of developmental processes. In W.Damon \& R. M.Lerner (Eds.), Handbook of child psychology, Vol. 1: Theoretical models of human development (5th ed., pp. 993-1023). New York: Wiley.

Bronfenbrenner, U., \& Morris, P. A. (2006). The bioecological model of human development. In W.Damon \& R. M.Lerner (Eds.), Handbook of child psychology, Vol. 1: Theoretical models of human development (6th ed., pp. 793-828). New York: Wiley.

Cassard, A. \& Sloboda, B. (2014). Leading the charge for SoTL - Embracing collaboration. Insight: A Journal of Scholarly Teaching, 9, 44-53.

Chapman, L., \& Ludlow, L. (2010). Can downsizing college class sizes augment student outcomes? An investigation of the effects of class size on student learning. The Journal of General Education, 59, 105-123.

Christenbury, L. (2011). The flexible teacher. The Effective Educator, 68, 46-50.

Driscoll, M. P. (2000). Psychology of learning for instruction. ( $2^{\text {nd }}$ ed.), Needham Heights, MA: Allyn and Bacon.

Felten, P. (2013). Principles of good practice in SoTL. Teaching and Learning Inquiry, 1, 121125.

Frisby, B. N., \& Myers, S. A. (2008). The Relationships among Perceived Instructor Rapport, Student Participation, and Student Learning Outcomes. Texas Speech Communication Journal, 33, 27-34.

Galotti, K. M., \& Clare, L. R. (2014). Goals, styles, and decisions: Changes and interactions during the first year of college. The American Journal of Psychology, 127, 383-396.

Hamilton, L. T. (2013). More is more or more is less? Parental financial investments during college. American Sociological Review, 78, 70-95.

Harper, S. R. (2009). Niggers no more: A critical race counternarative on black male student achievement at predominantly white colleges and universities. International Journal of Qualitative Studies in Education (QSE), 22, 697-712.

Hearn, J. C., \& Holdsworth, J. M. (2002). Influences of state-level policies and practices on college students' learning. Peabody Journal of Education, 77, 6-39.

Hill, L. H. (2014). Graduate students' perspectives on effective teaching. Adult Learning, 25, 5765.

Journal of the Scholarship of Teaching and Learning, Vol. 17, No. 2, April 2017.

josotl.indiana.edu 
Howie, D. (2013). Teaching thinking: A three-tiered model to enhance inclusive learning, in an ecological framework. Transylvanian Journal of Psychology. 2013 Special Issue, 33-50.

Jenkins, C. R., \& Speck, B. W. (2007). “I'm in their corner": Caring as a foundational to effective teaching. Journal on Excellence in College Teaching, 18 (2)

Kern, B., Mettetal, G., Dixson, M. D., \& Morgan, R. K. (2015). The role of SoTL in the academy: Upon the $25^{\text {th }}$ anniversary of Boyer's Scholarship Reconsidered. Journal of the Scholarship for Teaching and Learning, 15, 1-14.

McGlynn, A. P. (2008). Millennials in college: How do we motivate them? Education Digest, $73,19-22$.

Micari, M., \& Pazos, P. (2012). Connecting to the professor: Impact of the student-faculty relationship in a highly challenging course. College Teaching, 60, 41-47.

Michel, N., Cater, J. III, \& Varela, O. (2009). Active versus passive teaching styles: An empirical study of student learning outcomes. Human Resource Development Quarterly, 20, 397418.

Mupinga, D. M., Nora, R. T., \& Yaw, D. C. (2006). The learning styles, expectations, and needs of online students. College Teaching, 54, 185-189.

National Survey of Student Engagement. (2012). Promoting Student Learning and Institutional Improvement: Lessons from NSSE at 13. Bloomington, IN: Indiana University Center for Postsecondary Research.

Orr, A. C., \& Hammig, S. B. (2009). Inclusive postsecondary strategies for teaching students with learning disabilities: A review of the literature. Learning Disability Quarterly, 32, 181-196.

Pascarella, E. T., Pierson, C. T., Wolniak, G. C., \& Terenzini, P. T. (2004). First generation college students. The Journal of Higher Education, 75, 249-284.

Sagayadevan, V., \& Jeyaraj, S. (2012). The role of emotional engagement in lecturer-student interaction and the impact on academic outcomes of student achievement and learning. Journal of the Scholarship of Teaching and Learning, 12, 1-30.

Savage, H., Karp, R. S., \& Logue, R. (2004). Faculty mentorship at colleges and universities. College Teaching, 52, 21-24.

Stewart, E. B. (2006). Family- and individual-level predictors of academic success for African American students: A longitudinal path analysis utilizing national data. Journal of Black Studies, $36,597-621$.

Synnott, K. C. (2015). Smartphones in the classroom as impediments to student learning. Journal on Excellence in College Teaching, 26, 161-168.

Journal of the Scholarship of Teaching and Learning, Vol. 17, No. 2, April 2017.

josotl.indiana.edu 
Tudge, J. R. H., Mokrova, I., Hatfield, B., \& Karnik, R. B. (2009). Uses and misuses of Bronfenbrenner's bioecological theory of human development. Journal of Family Theory and Review, 1, 198-210.

Weaver, R., \& Qi, J. (2005). Classroom organization and participation: College students' perceptions. Journal of Higher Education, 76, 570-601.

Wentzell, G. W., Richlin, L., \& Cox, M. D. (2010). Effective and ineffective teaching: A message from the editors. Journal on Excellence in College Teaching, 21 (4).

Yoder, J. D., \& Hochevar, C. M. (2005). Encouraging active learning can improve students' performance on examinations. Teaching of Psychology, 32, 91-95. 